\title{
Clinical and radiographic evaluation of Bio-Gen with biocollagen compared with Bio-Gen with connective tissue in the treatment of class II furcation defects: a randomized clinical trial
}

\author{
Niloofar JENABIAN ${ }^{1}$, Sina HAGHANIFAR ${ }^{2}$, Avideh MABOUDI ${ }^{3}$, Ali BIJANI ${ }^{4}$
}

\footnotetext{
1- Department of Periodontics, Dental Faculty, Dental Materials Research Center, Babol University of Medical Sciences, Babol, Iran

2- Department of Radiology, Dental Faculty, Dental Materials Research Center, Babol University of Medical Sciences, Babol, Iran.

3- Department of Periodontics, Dental Faculty, Diabetes Research Center, Mazandaran University of Medical Sciences, Sari, Iran.

4- General Practitioner, Social Determinants of Health Research Center, Babol University of Medical Sciences, Babol, Iran.
}

Corresponding address: Avideh Maboudi - Department of Periodontics, Dental Faculty, Mazandaran University of Medical - Sciences - Khazar Avenue, Near Toba Center - Sari - Iran - Phone: +0098 1513244894 - Fax: +0098 1513244894 - e-mail: avideh48188@yahoo.com

Submitted: January 28, 2013 - Modification: May 25, 2013 - Accepted: July 02, 2013

\section{ABSTRACT}

\begin{abstract}
bjective: Treatment of furcation defects are thought to be challenging. The purpose of this study was to evaluate the clinical and radiographic parameters of Bio-Gen with Biocollagen compared with Bio-Gen with connective tissue in the treatment of Class II furcation defects. Material and Methods: In this clinical trial, 24 patients with Class II furcation defect on a buccal or lingual mandibular molar were recruited. After oral hygiene instruction, scaling and root planing and achievement of acceptable plaque control, the patients were randomly chosen to receive either connective tissue and Bio-Gen (case group) or Biocollagen and Bio-Gen (control group). The following parameters were recorded before the first and re-entry surgery (six months later): vertical clinical attachment level (VCAL), gingival index (GI), plaque index (PI), horizontal probing depth (HPD), vertical probing depth (VPD), gingival recession (GR), furcation vertical component (FVC), furcation to alveolar crest (FAC), fornix to base of defect (FBD), and furcation horizontal component (FHC) were calculated at the time of first surgery and during re-entry. A digital periapical radiograph was taken in parallel before first surgery and re-entry. The radiographs were then analyzed by digital subtraction. The differences with $\mathrm{p}$ value $<0.05$ were considered significant. Results: Only the mean changes of FAC, FHC, mean of FHC, FBD in re-entry revealed statistically significant differences between the two groups. HPD, VPD, FBD, FAC, and FHC showed statistically significant differences after 6 months in the case group. However, in the control group, statistically significant differences were found in GR and HPD. We did not observe any significant difference in radiographic changes among the two groups. Conclusion: The results of this trial indicate that better clinical outcomes can be obtained with connective tissue grafts in combination with bone material compared with a resorbable barrier with bone material. The differences in radiographic changes between the two groups, however, were not statistically significant.
\end{abstract}

Keywords: Furcation defects. Treatment. Guided tissue regeneration. Connective tissue.

\section{INTRODUCTION}

Periodontitis is a multifactorial disease accompanied by bone resorption ${ }^{25}$. Many factors can influence the prognosis of periodontally involved tooth ${ }^{1,12}$. Furcation defects can be one of the criteria considered by dentists to indicate the extraction of periodontally involved teeth ${ }^{20}$, and their treatments are thought to be challenging ${ }^{19}$. Various methods have been suggested for the treatment of furcation defects, including root resection, open flap debridement, odontoplasty, closed and open root preparation, regeneration, and extraction ${ }^{29}$. Regeneration of the periodontium within the furcation defect is one of 
the challenging aspects of periodontal therapy ${ }^{18}$. Initiation of osteogenesis and cementogenesis is a problem central to periodontal regeneration ${ }^{24}$. In guided tissue regeneration, resorbable and non-resorbable membranes are applied along with different bone materials in order to maintain space in bony defects and furcation $n^{6,8,26,28,30}$. One study showed that some genes are differentially expressed in membrane barrier-led periodontal healing compared with flap surgery alone, and this may account for the clinical outcome achieved by guided tissue regeneration ${ }^{16}$. Kwan, Lekovic and Camargo ${ }^{13}$ (1998) showed the use of connective tissue derived from patient tissue compared to flap debridement in treatment of interproximal periodontal defects could result in more gain in clinical attachment and osseous defect fill. Lekovic, et al. ${ }^{15}$ (1998) showed connective tissue in comparison with coronally positioned flaps in treatment of Class II furcation defects could achieve similar clinical resolution and better bone fill. Bouchard, Ouhayoun and Nilveus ${ }^{5}$ (1993) demonstrated that connective tissue grafts and expanded polytetrafluoroethylene membranes had comparable potential in supporting bone regeneration in mandibular Class II furcation lesions. Belal, et al. $^{3}$ (2005) also showed that connective tissue might be used as an alternative to polyglycolic acid/polylactic acid bioabsorbable membrane with comparable potential. Deo and Bongade ${ }^{9}$ (2008) demonstrated that connective tissue graft could cause better soft tissue closure of furcation in comparison with resorbable collagen membrane. In the present study, we used Mixed Bio-Gen ${ }^{\circledR}$ (Bioteck-Italy) bone material that consists of spongy (diameter, $1 \mathrm{~mm}$ ) and cortical (diameter, $0.5 \mathrm{~mm}$ ) particles of horse femur. The manufacturer of this product suggests a resorption time of 4-6 and 8-12 months for spongy and cortical bone, respectively. The composition of these particles in mixed Bio-Gen dictates the resorption time. We used Biocollagen ${ }^{\circledR}$ (horse origin, deantigenised, and lypophilized) as one of the membranes and autogenous connective tissue as the other. As few studies had compared the use of resorbable membranes with connective tissue in treatment of Class II furcation defects $3,5,9$, and their results were controversial as well, this study aimed at evaluating the clinical and radiographic parameters of Bio-Gen with Biocollagen compared with Bio-Gen with connective tissue in the treatment of Class II furcation defects.

\section{MATERIAL AND METHODS}

\section{Study design}

This study was a single-center, balanced (1:1), randomized, double-blind, parallel group clinical trial study that was conducted in Iran.

\section{Patients}

We selected 24 patients with Class II buccal or lingual furcation defects on the first or the second molars and mild-moderate chronic periodontitis, who had been referred to the Faculty of Dentistry of Babol University of Medical Sciences. The subjects were enrolled from December 2009 to June 2010. This department serves $>1.7$ million local residents of three cities (Amol, Babol, and Ghaemshahr) and the corresponding urban regions in Mazandaran and locations across the Caspian Sea. During the study period, we had the opportunity to contact the patients by telephone. The inclusion criteria for this study were 30-60 age, good general health, good oral hygiene after initial periodontal therapy (plaque control record $\geq 90 \%{ }^{21}$ ), vital teeth or non-vital teeth treated endodontically with clinical or radiographic evidence of periapical pathology, and a mandibular molar with a buccal or lingual degree II furcation defect $\geq 3 \mathrm{~mm}$ of horizontal probing depth but not entirely through furcation ${ }^{10}$. The exclusion criteria for this study were contraindications to periodontal surgery, smoking, caries or restoration of furcation, tooth mobility exceeding Miller Class $\mathrm{II}^{14}$, cervical enamel projection, or another dental anatomical anomaly in tooth.

\section{Sample size}

The sample size for each group was estimated to be 12 cases according to the study of Belal, et al. ${ }^{3}$ (2005). The change in furcation horizontal component $(\mathrm{FHC})$ in both groups was considered $0.5(\delta)$, and the expected mean different changes were considered 0.6 . The $a$ and $\beta$ errors chosen for these calculations were 0.05 and 0.02 , respectively.

\section{Randomization}

\section{Sequence generation}

We prepared 24 small sheets of paper, and wrote Biocollagen/Bio-Gen on 12 sheets and connective tissue/Bio-Gen on 12 sheets. The small sheets of paper were folded and placed in a small box and mixed together.

\section{Allocation concealment}

Before the initial surgery, the patients picked the sheets of paper from the box. The therapy that was written on it was the therapy that the patient received. We could not predict the therapy for any patient.

\section{Ethics approval}

This study was approved by the Department of Periodontics, Faculty of Dentistry, Research and Ethics Committee of Babol University of Medical Sciences. After the procedures were described, the patients agreed to participate by signing an informed consent form. This study was registered with the 
Iranian Registry of Clinical Trials (www.irct.ir) with registration number ID:IRCT201102195861N1.

\section{Implementation}

The surgical procedures and pre- and postsurgical care were done by a surgeon (A.M). Radiographic procedures were carried out by a radiologist (S.H.). All clinical measurements were carried out by a calibrated examiner (N.J.). The analyzer (A.B) and calibrated examiner (N.J) were blinded to the treatment procedures.

\section{Examiner calibration}

The investigator who was responsible for clinical measurements (N.J.) was calibrated for intraexaminer repeatability before the trial. Before the beginning of trial, five patients with chronic periodontitis were enrolled for this aim. The clinical parameters were assessed in the left and right mandibulary first and second molars of each patient. Duplicate measurements $(\mathrm{N}=320)$ were performed with an interval of 7 days between the first and second recording. The intraclass correlation coefficients (Pearson correlation coefficients) as a measure of intraexaminer reproducibility were $0.85,0.82,088$, and 0.80 for GR, VPD, VCAL, HPD, respectively.

\section{Clinical and radiographic measurements}

The Williams periodontal probe was used to measure the parameters. Vertical clinical attachment level (VCAL), gingival index $(\mathrm{GI})^{17}$, plaque index $(P I)^{27}$, horizontal probing depth (HPD), vertical probing depth (VPD), gingival recession (GR) were measured just before the first surgery and reentry surgery ( 6 months later). The intrasurgical parameters furcation vertical component (FVC), furcation to alveolar crest (FAC), fornix to base of defect (FBD), and furcation horizontal component (FHC) were measured at the time of the first surgery and during re-entry surgery.
A periapical radiograph was obtained with a parallel digital method (long cone) using photostimulable phosphor (PSP, Digora Optime ${ }^{\circledR}$ Soredex, Helsinki, Finland) before surgery and 6 months after surgery. Before taking radiographs, the occlusion in each patient was recorded with acrylic resin (Duralay ${ }^{\circledR}$, Reliance Dental Manufacturing Co, Worth, IL, USA). Six months later, before re-entry surgery, this acrylic bite block was used for each radiograph in order to ensure that the teeth and film were in a constant relative position on every occasion. The digital images then were superimposed in the Adobe Photoshop CS4 program (Adobe Systems Inc., San Jose, CA) and subtraction was performed. Changes in the density and volume of bone were detected as lighter areas (bone gain) or dark areas (bone loss).

\section{Interventions \\ Initial therapy}

Initial therapy included oral hygiene instruction and scaling and root planing (SRP) with ultrasonic device (Woodpecker ${ }^{\circledR}$, Guilin Woodpecker Medical Instrument Co, Guangxi, China), and occlusal adjustment were done for each patient in case necessity. Achievement of plaque control record $\geq 90 \%$ was acceptable before surgery ${ }^{17,21}$.

\section{The surgical procedure \\ The first surgery}

The surgeries were performed in the same method (using different membranes) and by the same surgeon in the case and control groups.

The surgical procedures consisted of local anesthesia (Persocaine- $\mathrm{E}^{\circledR}$ Lidocaine $\mathrm{Hcl} 2 \%$, Epinephrine 1:80,000, Daroupakhsh Co., Tehran, Iran), sulcular incision, reflection of the flap, granulation tissue debridement, thorough SRP with ultrasonic device (Woodpecker ${ }^{\circledR}$, China), and normal saline irrigation. In the case group, the connective tissue was removed from the undersurface of the palatal flap in maxillary first and the second

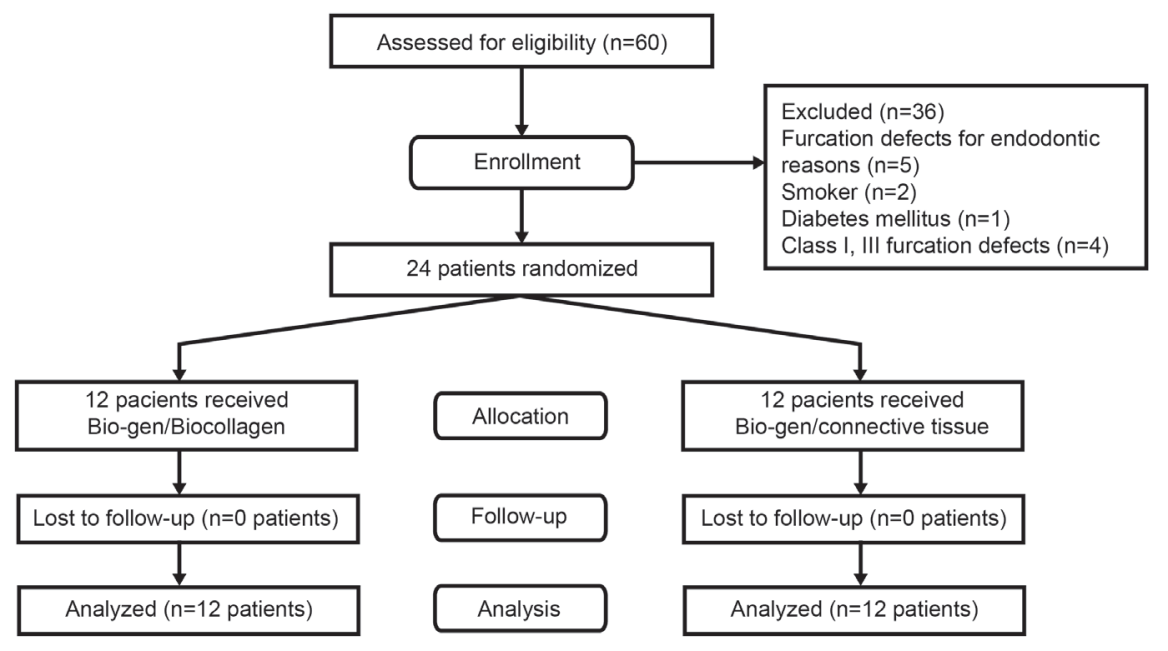

Figure 1- Flow chart summarizing the study process in the two treatment groups 
premolars and first molar.Depending on the side of furcation involvement -- right or left -- the side of the palatal flap was chosen on the same side. The area was sutured with silk 0-4. Bio-Gen was mixed with normal saline before use. Furcation defect was filled with Bio-Gen, connective tissue was placed on BioGen, and the flap was sutured with silk 0-4. In the control group, Bio-Gen and Biocollagen were mixed by normal saline separately. The procedures were performed as the case group: the furcation defects were filled with Bio-Gen, but Biocollagen was placed on the defects instead of connective tissue. The area was covered with periodontal dressing (COE-PAK ${ }^{\mathrm{TM}}$, GC America Inc., Alsip, IL, USA) and after 14 days, the dressing and sutures were removed.

\section{Re-entry surgery}

Surgical re-entry procedure was performed after 6 months. Following intrasulcular incisions, a mucoperiosteal flap was elevated on the facial or lingual aspect of the treated furcation and rinsed with normal saline, and the intrasurgical parameters were measured. Afterwards, the flap was reapproximated and sutured with silk 4-0.

\section{Post-surgical care}

After surgery, the patients took $500 \mathrm{mg}$ amoxicillin three times daily for 8 days, and rinsed their mouths with chlorhexidine gluconate (Shahre Darou Inc., Tehran, Iran) three times a day for 6 weeks. Professional dental cleaning was done with a rubber cap and chlorhexidine gel every week for 8 weeks, and then periodontal maintenance was performed

Table 1- Gingival index $(\mathrm{Gl})$ and plaque index $(\mathrm{PI})$ at baseline, before surgery, before re-entry and their comparison between control and case groups. SD = standard deviation

\begin{tabular}{|c|c|c|c|c|c|}
\hline \multirow[t]{2}{*}{ Parameters } & \multicolumn{2}{|c|}{ Control group } & \multicolumn{2}{|c|}{ Case group } & \multirow[b]{2}{*}{$\begin{array}{c}\text { P value } \\
\text { (Mann-Whitney) }\end{array}$} \\
\hline & Median & Mean $\pm S D$ & Mean \pm SD & Median & \\
\hline \multicolumn{6}{|l|}{$\mathrm{GI}$} \\
\hline Baseline & 1.5 & $1.5 \pm 0.52$ & $1.67 \pm 0.49$ & 2 & 0.51 \\
\hline Before surgery & 1 & $0.83 \pm 0.38$ & $0.67 \pm 0.49$ & 1 & 0.51 \\
\hline Before re-entry & 1 & $0.67 \pm 0.49$ & $0.67 \pm 0.49$ & 1 & 1 \\
\hline \multicolumn{6}{|l|}{$\mathrm{PI}$} \\
\hline Baseline & 2 & $2 \pm 0.85$ & $2.33 \pm 0.49$ & 2 & 0.37 \\
\hline Before surgery & 1 & $0.67 \pm 0.49$ & $1.17 \pm 0.38$ & 1 & 0.68 \\
\hline Before re-entry & 0 & $0.17 \pm 0.38$ & $0.33 \pm 0.49$ & 0 & 0.51 \\
\hline
\end{tabular}

Table 2- Gingival index ( $\mathrm{Gl}$ ) and plaque index (PI) at baseline, before surgery, before re-entry and their comparison between control and case groups. SD = standard deviation

\begin{tabular}{|c|c|c|c|c|}
\hline \multicolumn{5}{|c|}{ Case group } \\
\hline Parameters & Mean士SD & Parameters & Mean $\pm S D$ & $\begin{array}{c}\text { P value } \\
\text { (Wilcoxon) }\end{array}$ \\
\hline \multicolumn{5}{|l|}{$\mathrm{Gl}$} \\
\hline Baseline & $1.67 \pm 0.49$ & Before surgery & $0.67 \pm 0.49$ & $0.001^{*}$ \\
\hline Before surgery & $0.67 \pm 0.049$ & Before re-entry & $0.67 \pm 0.49$ & 1 \\
\hline Baseline & $1.67 \pm 0.49$ & Before re-entry & $0.67 \pm 0.49$ & $0.001^{*}$ \\
\hline \multicolumn{5}{|l|}{ PI } \\
\hline Baseline & $2.33 \pm 0.49$ & Before surgery & $1.17 \pm 0.38$ & $0.004^{*}$ \\
\hline Before surgery & $1.17 \pm 0.38$ & Before re-entry & $0.33 \pm 0.49$ & $0.002^{*}$ \\
\hline Baseline & $2.33 \pm 0.49$ & Before re-entry & $0.33 \pm 0.49$ & $0.002^{*}$ \\
\hline \multicolumn{5}{|l|}{ Control group } \\
\hline \multicolumn{5}{|l|}{ GI } \\
\hline Baseline & $1.5 \pm 0.52$ & Before surgery & $0.83 \pm 0.38$ & $0.005^{*}$ \\
\hline Before surgery & $0.83 \pm 0.38$ & Before re-entry & $0.67 \pm 0.49$ & 0,157 \\
\hline Baseline & $1.5 \pm 0.52$ & Before re-entry & $0.67 \pm 0.49$ & $0.002^{*}$ \\
\hline \multicolumn{5}{|l|}{ PI } \\
\hline Baseline & $2 \pm 0.85$ & Before surgery & $0.67 \pm 0.49$ & $0.001^{*}$ \\
\hline Before surgery & $0.67 \pm 0.49$ & Before re-entry & $0.17 \pm 0.38$ & $0.014^{*}$ \\
\hline Baseline & $2 \pm 0.85$ & Before re-entry & $0.17 \pm 0.38$ & $0.002^{*}$ \\
\hline
\end{tabular}

*Significant difference compared with controls $(p<0.05)$ 
every 2 months until the date of the re-entry surgery.

\section{Statistical methods}

The data were analyzed by SPSS 15 . Student's $t$ test and Mann-Whitney test were used to compare the parameters between the case and control groups. Wilcoxon and paired $t$ tests were used to compare the parameters within each group. The differences with $p$ value $<0.05$ were considered significant. All $p$ values are two-tailed and all parameters were represented by mean \pm SD. Medians of GI, PI were mentioned too.

\section{RESULTS}

All 24 patients completed the study protocol ( 10 men, 14 women) (Figure 1).

There were 7 lingual and 5 buccal furcation involvements in the case group and 8 lingual and 5 buccal furcation involvements in the control group. No statistically significant differences on parameters were observed within the case group in the lingual and buccal furcation involvements as well as within the control group (with ANOVA). All surgical procedures were performed without complications, yielding minimal postoperative discomfort with no infections reported or observed.

Table 3- Comparison of clinical parameters and their changes between the case and control groups

\begin{tabular}{|c|c|c|c|c|}
\hline Parameter & Control group & Case group & & \\
\hline & Mean士SD & Mean士SD & $\begin{array}{c}\text { P value } \\
\text { (Mann-Whitney) }\end{array}$ & $P$ value (t-test) \\
\hline \multicolumn{5}{|l|}{$\mathrm{GR}$} \\
\hline Before first surgery & $1.29 \pm 1.54$ & $0.91 \pm 0.84$ & 0.83 & 0.46 \\
\hline Before re-entry & $1.79 \pm 1.73$ & $1.04 \pm 0.96$ & 0.31 & 0.2 \\
\hline Changes & $-0.5 \pm 0.42$ & $0.12 \pm 0.28$ & 0.06 & 0.05 \\
\hline \multicolumn{5}{|l|}{ VPD } \\
\hline Before first surgery & $3.92 \pm 2.31$ & $3.25 \pm 1.42$ & 0.24 & 0.4 \\
\hline Before re-entry & $3.41 \pm 2.02$ & $2.87 \pm 1.35$ & 0.51 & 0.44 \\
\hline Changes & $0.5 \pm 0.79$ & $0.37 \pm 0.48$ & 0.61 & 0.64 \\
\hline \multicolumn{5}{|l|}{ HPD } \\
\hline Before first surgery & $3.67 \pm 0.65$ & $3.50 \pm 0.67$ & 0.55 & 0.54 \\
\hline Before re-entry & $3.33 \pm 0.77$ & $2.50 \pm 1.44$ & 0.14 & 0.09 \\
\hline Changes & $0.33 \pm 0.49$ & $1 \pm 1.20$ & 0.17 & 0.09 \\
\hline \multicolumn{5}{|l|}{ VCAL } \\
\hline Before first surgery & $5.16 \pm 3.62$ & $4.1 \pm 1.77$ & 0.44 & 0.38 \\
\hline Re-entry & $5.08 \pm 3.57$ & $3.87 \pm 2.03$ & 41 & 0.32 \\
\hline Changes & $0.83 \pm 0.92$ & $0.25 \pm 0.65$ & 79 & 0.61 \\
\hline \multicolumn{5}{|l|}{ FBD } \\
\hline First surgery & $2.55 \pm 0.67$ & $2.42 \pm 1.24$ & 0.63 & 0.84 \\
\hline Re-entry & $2.42 \pm 0.90$ & $1.33 \pm 1.82$ & $0.02^{*}$ & 0.07 \\
\hline Changes & $0.83 \pm 0.51$ & $1.08 \pm 1.56$ & 0.14 & 0.05 \\
\hline \multicolumn{5}{|l|}{ FAC } \\
\hline First surgery & $1.75 \pm 0.75$ & $1.92 \pm 0.79$ & 0.63 & 0.6 \\
\hline Re-entry & $1.83 \pm 0.93$ & $1.08 \pm 1.37$ & 0.08 & 0.13 \\
\hline Changes & $0.83 \pm 0.28$ & $0.83 \pm 1.19$ & 0.06 & $0.02^{*}$ \\
\hline \multicolumn{5}{|l|}{ FVC } \\
\hline First surgery & $0.75 \pm 0.62$ & $0.50 \pm 0.79$ & 0.31 & 0.4 \\
\hline Re-entry & $0.58 \pm 0.51$ & $0.25 \pm 0.62$ & 0.12 & 0.16 \\
\hline Changes & $0.16 \pm 0.38$ & $0.25 \pm 0.62$ & 0.97 & 0.69 \\
\hline \multicolumn{5}{|l|}{$\mathrm{FHC}$} \\
\hline First surgery & $3.33 \pm 0.65$ & $3.17 \pm 0.57$ & 0.75 & 0.51 \\
\hline Re-entry & $3.25 \pm 0.75$ & $1.67 \pm 1.82$ & 0.06 & $0.01^{*}$ \\
\hline Changes & $0.83 \pm 0.51$ & $1.5 \pm 1.67$ & 0.52 & $0.01^{*}$ \\
\hline
\end{tabular}

FAC, furcation to alveolar crest; FBD, fornix to base of defect; FHC, furcation horizontal component; FVC, furcation vertical component; GR, gingival recession; HPD, horizontal probing depth; VCAL, vertical clinical attachment level; VPD, vertical probing depth; SD = standard deviation; * Statistical significance, $\mathrm{p}<0.05$ 
Plaque index (PI) and gingival index (GI)

Oral hygiene, monitored by full-mouth plaquecontrol scores, was maintained throughout the study and was sustained within acceptable levels ( $<10 \%$ of the sites exhibited plaque) (data not shown).
PI and GI were reduced in both groups, but no statistically significant difference was found between them (Table 1).

There were statistically significant differences in PI and GI within each group, except GI before first

Table 4- Comparison of clinical parameters at first surgery and re-entry within the case

\begin{tabular}{|c|c|c|c|c|c|c|}
\hline \multirow{3}{*}{ Parameters } & \multicolumn{3}{|c|}{ Control group } & \multicolumn{3}{|c|}{ Case group } \\
\hline & $\begin{array}{l}\text { Before } \\
\text { surgery }\end{array}$ & 6 months later & & $\begin{array}{l}\text { Before } \\
\text { surgery }\end{array}$ & 6 months later & \\
\hline & Mean $\pm S D$ & Mean $\pm S D$ & $\begin{array}{c}\text { p.value } \\
\text { (paired } t \text { test) }\end{array}$ & Mean $\pm S D$ & Mean $\pm S D$ & $\begin{array}{c}\text { p.value } \\
\text { (paired t test) }\end{array}$ \\
\hline GR & $1.29 \pm 1.54$ & $1.79 \pm 1.73$ & $0.02^{*}$ & $0.91 \pm 0.84$ & $1.04 \pm 0.96$ & 0.389 \\
\hline VPD & $3.92 \pm 2.31$ & $3.41 \pm 2.02$ & 0.053 & $3.25 \pm 1.42$ & $2.87 \pm 1.35$ & $0.021^{*}$ \\
\hline HPD & $3.67 \pm 0.65$ & $3.33 \pm 0.77$ & $0.039^{*}$ & $3.50 \pm 0.67$ & $2.50 \pm 1.44$ & $0.015^{*}$ \\
\hline VCAL & $5.16 \pm 3.62$ & $5.08 \pm 3.57$ & 0.761 & $4.12 \pm 1.77$ & $3.87 \pm 2.03$ & 0.214 \\
\hline FBD & $2.42 \pm 1.24$ & $2.42 \pm 0.90$ & 0.58 & $2.42 \pm 1.24$ & $1.33 \pm 1.82$ & $0.035^{*}$ \\
\hline FAC & $1.75 \pm 0.75$ & $1.83 \pm 0.93$ & 0.33 & $1.92 \pm 0.79$ & $1.08 \pm 1.37$ & $0.034^{*}$ \\
\hline FVC & $0.75 \pm 0.62$ & $0.58 \pm 0.51$ & 0.16 & $0.5 \pm 0.79$ & $0.25 \pm 0.62$ & 0.191 \\
\hline $\mathrm{FHC}$ & $3.25 \pm 0.75$ & $3.33 \pm 0.65$ & 0.58 & $3.17 \pm 0.57$ & $1.67 \pm 1.82$ & $0.01^{*}$ \\
\hline
\end{tabular}

FAC, furcation to alveolar crest; FBD, fornix to base of defect; FHC, furcation horizontal component; FVC, furcation vertical component; GR, gingival recession; HPD, horizontal probing depth; VCAL, vertical clinical attachment level; VPD, vertical probing depth. * Statistical significance, $p<0.05$
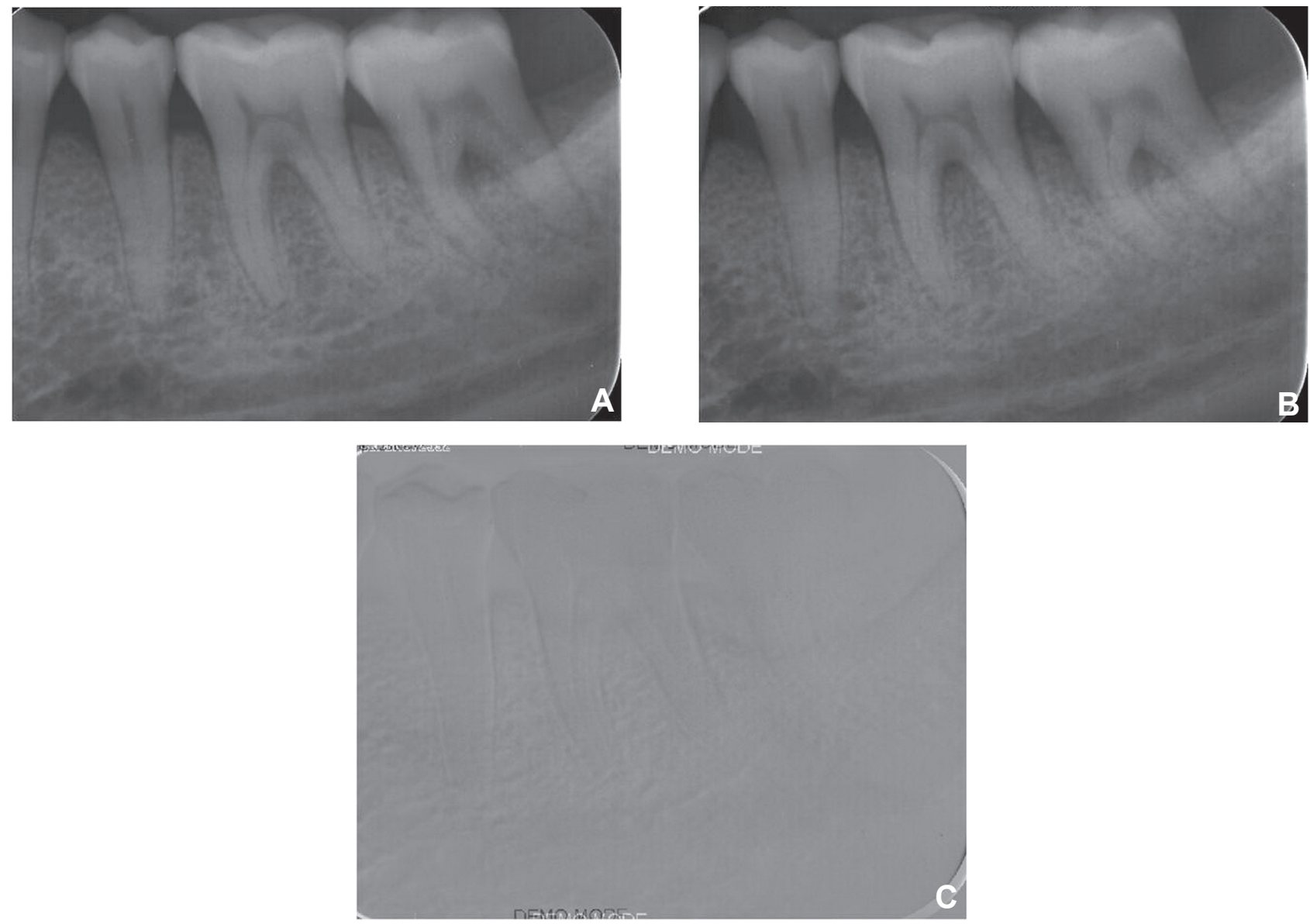

Figure 2- (A) Radiograph taken with photostimulable phosphor (psp) before surgery. (B) Radiograph taken by the same method six months later. (C) Digital subtraction performed with Adobe Photoshop CS4 software 
surgery and re-entry (Table 2).

\section{Clinical parameters}

Only the mean changes of FAC, FHC, the mean of FHC, FBD in re-entry showed statistically significant differences between the two groups (Table 3 ). HPD, VPD, FBD, FAC, and FHC showed statistically significant differences after 6 months in the case group. In the control group, only GR and HPD revealed statistically different differences after 6 months (Table 4).

\section{Radiographic parameters}

Radiographic changes between the two groups were not significantly different (data not shown) (Figure 2).

\section{DISCUSSION}

Treatment of furcation defects are thought to be one of the most challenging procedures in periodontal theraphy ${ }^{22}$. Regenerative theraphy of furcation defect is challenging as well ${ }^{18}$. In guided tissue regeneration, resorbable and non-resorbable membranes are applied along with different bone materials ${ }^{26,30}$. Connective tissue was used in some researches as membrane for treatment of interproximal and furcation defects $3,5,9,13,15$, indicating controversial results. Therefore, we decided to evaluate the clinical and radiographic parameters of Bio-Gen with Biocollagen compared with Bio-Gen with connective tissue in the treatment of Class II furcation defects in this study.

There were no statistically significant differences in the mean of GI and PI between the case and control groups. This may indicate the level of oral hygiene in the case and control groups at each time. The statistically significant mean difference in GI and PI at the baseline and before surgery in the case and control groups indicates improvement of oral hygiene level and decrease in inflammation as a result of regular recall accompanied by oral hygiene instruction before surgery. The level of plaque control before a periodontal regenerative procedure is critical to get the best results. The presence of poor plaque control in dose-dependent manner is associated with poor clinical outcomes ${ }^{11,12,23}$. The statistically significant differences in the mean of PI before surgery and 6 months later in the case and control groups are the results of professional dental cleaning with a rubber cap and chlorhexidine gel every week up to 8 weeks and monthly regular patient recall until re-entry.

Statistically significant differences in FAC, FHC, and changes of FHC, FBD between the two groups at first surgery and re-entry occurred due to more bone formation in case group which could be related to more support and protection of the wound of the furcation site during the healing period via connective tissue ${ }^{9}$. Increase of gingival recession after 6 months happened in both groups. After healing in all periodontal procedures, gingival recession is inevitable. Limiting recession is one of the aims of regenerative procedures ${ }^{7,9}$. The nonsignificant difference of recession 6 months after surgery compared with before surgery in the case group could indicate achievement of one objective of regenerative procedures (limiting of recession). It is perhaps due to the development of a thick biotype in the connective tissue group that was more resistant to recession. Anderegg, Metzler and $\mathrm{Nicoll}^{2}$ (2005) demonstrated that the sites with a gingival thickness of $>1 \mathrm{~mm}$ had less GR post-surgery than those with a gingival thickness of $<1 \mathrm{~mm}$. The authors concluded that the thickness of gingival tissue covering the bone material must be considered in order to reduce post treatment gingival recession ${ }^{2}$. Higher GR in the synthetic membrane group compared with the connective tissue group was also observed in other studies $3,4,9$. The significant difference in VPD and HPD in the case group before surgery and 6 months later is probably due to stronger gingival fibers as a result of the establishment of long junctional epithelium and increase in FBD, FAC, and FHC after surgery. The statistical significance of most parameters in the case groups, in addition to the lack of statistical significance of radiographic changes in the case and control group, may be related to the small sample size or necessity for more time to mineralization.

The small sample size and short-term evaluation ( 6 months after surgery) could be mentioned as the limitations of this study.

\section{CONCLUSION}

The evaluation term and number of patients for this study do not permit a conclusion that favors one procedure over the other. It might be assumed that better clinical outcomes could be obtained if connective tissue grafts were used in combination with bone materials rather than resorbable barriers with bone materials. Radiographic changes between the case and control groups, however, were not statistically significant.

\section{ACKNOWLEDGMENTS}

The authors thank Dr. Reza Alizade and Niloofar Shafiee for their comments during the preparation of the paper. This study was supported by a grant from the Vice Chancellery of Research Council of Babol University of Medical Sciences, Iran. This article was written based on Dr. Avideh Maboudi's specialty thesis done at Babol University of Medical Sciences. The authors report no conflicts of interest related to this study. 


\section{REFERENCES}

1- Amoian B, Haghanifar S, Vazinpour H, Bijani A. Clinical and radiographic evaluation of Osteora on Class II furcation defects in chronic periodontitis. J Babol Univ Med Sci. 2011;13:39-45.

2- Anderegg C, Metzeler D, Nicoll B. Gingival thickness in guided tissue regeneration and associated recession at facial furcation defects. J Periodontol. 1995;66:397-402.

3- Belal M, Al-Noamany F, El-Tonsy MM, El-Guindy HM, Ishikawa I. Treatment of human Class II furcation defects using connective tissue grafts, bioabsorbable membrane, and resorbable hydroxylapatite: a comparative study. J Int Acad Periodontol. 2005; 7:114-28.

4- Blumental NA. A clinical comparision of collagen membranes with e-PTFE membranes in the treatment of human mandibular buccal Class II defects. J Periodontol. 1993;64:925-33.

5- Bouchard P, Ouhayoun JP, Nilvéus RE. Expanded polytetrafluoroethylene membranes and connective tissue grafts support bone regeneration for closing mandibular Class II furcations. J Periodontol. 1993;64:1193-8.

6- Bowers GM, Schallhorn RG, McClain PK, Morrison GM, Morgan $R$, Reynolds MA. Factors influencing the outcome of regenerative therapy in mandibular Class II furcations: Part I. J Periodontol. 2003; 74:1255-68.

7- Cortellini $\mathrm{P}$, Tonetti MS. Regenerative periodontal theraphy. In: Lang NP, Lindhe J, editors. Clinical periodontology and implant dentistry. $5^{\text {th }}$ ed. Copenhagen: Munksgaard Blackwell; 2008. p.901-54.

8- De Leonardis D, Garg AK, Pedrazzoli V, Pecora GE. Clinical evaluation of the treatment of class II furcation involvements with bioabsorbable barriers alone or associated with demineralized freeze-dried bone allografts. J Periodontol. 1999;70:8-12.

9- Deo VD, Bongade ML. An evaluation of the effectiveness of connective tissue grafts as a barrier with bioresorbable collagen membrane in the treatment of mandibular Class II furcation in humans: a case report series of 20 cases. Perio. 2008;4:281-90. 10- Hamp SE, Nyman S, Lindhe J. Periodontal treatment of multirooted teeth. Results after 5 years. J Clin Periodontol. 1975;2:126-35.

11- Heytz-Mayfield L, Tonetti MS, Cortellini P, Lang NP; European Research Group on Periodontology (ERGOPERIO). Microbial colonization patterns predict the outcomes of surgical treatment of intrabony defects. J Clin Periodontol. 2006;33:62-8.

12- Huynh-Ba G, Kuonen P, Hofer D, Schmid J, Lang NP, Salvi GE. The effect of periodontal therapy on the survival rate and incidence of complications of multirooted teeth with furcation involvement after an observation period of at least 5 years: a systematic review. J Clin Periodontol. 2009;36:164-74.

13- Kwan SK, Lekovic V, Camargo PM, Klokkevold PR, Kenney EB, Nedic $M$, et al. The use of autogenous periostal grafts as barriers for the treatment of intrabony defects in humans. J Periodontol. 1998;69:1203-9.

14- Laster L, Laudenbach KW, Stoller NH. An evaluation of clinical tooth mobility measurements. J Periodontol. 1975;46:603-7.
15- Lekovic V, Klokkevold PR, Camargo PM, Kenney EB, Nedic $M$, Weinilaneder $M$. Evaluation of periosteal membranes and coronally positioned flaps in the treatment of Class II furcation defects: a comparative clinical study in humans. J Periodontol. 1998; 69:1050-5.

16- Lima LL, Gonçalves PF, Sallum EA, Casati MZ, Nociti FH Jr. Guided tissue regeneration may modulate gene expression in periodontal intrabony defects: a human study. J Periodontal Res. 2008;43(4):459-64.

17- Löe H, Silness J. Periodontal disease in pregnancy. I. Prevalence and severity. Acta Odontol Scand. 1963;21:533-51. 18- Lyons LC, Weltman RL, Moretti AJ, Trejo PM. Regeneration of degree II furcation defects with a $4 \%$ doxycycline hyclate bioabsorbable barrier. J Periodontol. 2008;79:72-9.

19- Marcaccini AM, Pavanelo A, Nogueira AC, Souza JA, Porciúncula $\mathrm{HF}$, Cirelli JA. Morphometric study of the root anatomy in furcation area of mandibular first molars. J Appl Oral Sci. 2012;20:76-81. 20- Moreira $\mathrm{CH}$, Zanatta FB, Antoniazzi R, Meneguetti PC, Rösing CK. Criteria adopted by dentists to indicate the extraction of periodontally involved teeth. J Appl Oral Sci. 2007;15:437-41.

21- O'Leary TJ, Drake RB, Naylor JE. The plaque control record. J Periodontol. 1972;43:38.

22- Pruthi VK, Gelskey SC, Mirbod SM. Furcation therapy with bioabsorbable collagen membrane: a clinical trial. J Can Dent Assoc. 2002;68:610-5.

23- Ribeiro EP, Bittencourt S, Sallum EA, Nociti FH Jr, Casati MZ. Non-surgical instrumentation associated with povidone-iodine in the treatment of interproximal furcation involvements. J Appl Oral Sci. 2010;18:599-606.

24- Ripamonti U, Reddi AH. Periodontal regeneration: potential role of bone morphogenetic proteins. J Periodontal Res. 1994;29:22535.

25- Rizzo A, Paolillo R, Guida L, Annunziata M, Bevilacqua N, Tufano $M A$. Effect of metronidazole and modulation of cytokine production on human periodontal ligament cells. Int Immunopharmacol. 2010;10:744-50.

26- Santana RB, Mattos CM, Francischone CE, Van Dyke T. Superficial topography and porosity of an absorbable barrier membrane impacts soft tissue response in guided bone regeneration. J Periodontol. 2010;81:926-33.

27- Silness J, Löe H. Periodontal disease in pregnancy. II. Correlation between oral hygiene and periodontal condition. Acta Odontol Scand. 1964;22:121-35.

28- Simonpietri-C JJ, Novaes AB Jr, Batista EL Jr, Filho EJ. Guided tissue regeneration associated with bovine-derived anorganic bone in mandibular class II furcation defects. 6-month results at re-entry. J Periodontol. 2000;71:904-11.

29- Walter C, Weiger R, Zitzmann NU. Periodontal surgery in furcation-involved maxillary molars revisited - an introduction of guidelines for comprehensive treatment. Clin Oral Invest. 2011;15:9-20.

30- Yukna RA, Yukna CN. Six-year clinical evaluation of HTR synthetic bone grafts in human grade II molar furcations. J Periodontal Res. 1997;32:627-33. 